
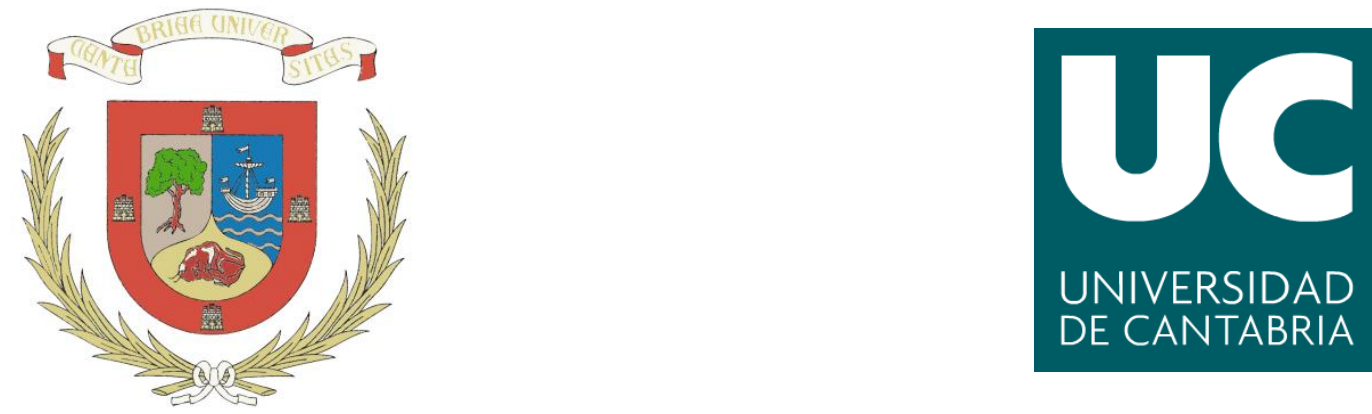

\title{
Trasplante de progenitores hematopoyéticos
}

Hematopoietic stem cell transplantation

\author{
Grado en enfermería
}

Facultad de Enfermería, Universidad de Cantabria

Curso 2018/19

Autor: Nestor Olmedo Murcia Isaza

Directora: Mercedes Lázaro Otero

Febrero 2019 


\section{AVISO RESPONSABILIDAD UC}

Este documento es el resultado del Trabajo Fin de Grado de un alumno, siendo su autor responsable de su contenido.

Se trata por tanto de un trabajo académico que puede contener errores detectados por el tribunal y que pueden no haber sido corregidos por el autor en la presente edición.

Debido a dicha orientación académica no debe hacerse un uso profesional de su contenido.

Este tipo de trabajos, junto con su defensa, pueden haber obtenido una nota que oscila entre 5 y 10 puntos, por lo que la calidad y el número de errores que puedan contener difieren en gran medida entre unos trabajos y otros,

La Universidad de Cantabria, el Centro, los miembros del Tribunal de Trabajos Fin de Grado, así como el profesor tutor/director no son responsables del contenido último de este Trabajo. 


\section{ÍNDICE}

$\begin{array}{ll}\text { 1. Resumen/Abstract } & \text { Pág. } 1\end{array}$

2. Introducción $\quad$ Pág. 2

3. Capítulos. Pág. 5

3.1 Trasplante de progenitores hematopoyéticos (TPH) Pág. 5

3.1.1 Definición y objetivo terapéutico del TPH Pág. 5

3.1.2 Tipos de trasplante según relación donante-receptor Pág. 6

3.1.3 Indicaciones y contraindicaciones del TPH Pág. 7

$\begin{array}{ll}3.2 \text { Proceso de donación } & \text { Pág. } 8\end{array}$

3.2.1 El donante de células hematopoyéticas $\quad$ Pág. 8

3.2.2 Marco legal de la donación Pág. 8

3.2.3 Obtención de los PH (Progenitores hematopoyéticos) Pág. 9

3.2.4 Extracción y procesamiento del material celular Pág. 10

3.2.5 Preparación del receptor Pág. 11

3.2.6 Complicaciones del proceso de TPH Pág. 11

3.3 Aspectos emocionales del paciente en tratamiento con PH Pág. 13

3.4 Plan de cuidados estandarizado de enfermería Pág. 14

$\begin{array}{ll}\text { 4. Bibliografía } & \text { Pág. } 21\end{array}$ 


\title{
Apéndice de Abreviaturas
}

\author{
AA: Anemia aplásica \\ AM: Aplasia medular \\ CM: Célula madre
}

CMH: Célula madre hematopoyética

CMV: Citomegalovirus

CPH: Células progenitoras hematopoyéticas

DMSO: Dimetil sulfóxido

EICH: Enfermedad de injerto contra el huésped

HLA: Antígeno leucocitario humano

LA: Leucemia aguda

LLA: Leucemia linfoblástica aguda

LLC: Leucemia linfoblástica crónica

LMA: Leucemia mieloide aguda

LMC: Leucemia mieloide crónica

MM: Mieloma múltiple

MO: Médula ósea

QT: Quimioterapia

REDMO: Red mundial de donantes de médula

RT: Radioterapia

SCU: Sangre de cordón umbilical

SEHH: Sociedad española de hematología y hemostasia

SOSH: Síndrome de obstrucción sinusoidal del hígado

SP: Sangre periférica

TPH: Trasplante progenitores hematopoyéticos 


\section{RESUMEN}

El Trasplante de Progenitores Hematopoyéticos (TPH), es una modalidad terapéutica para un grupo de patologías de carácter hematológico. Estas patologías dan como resultado una medula ósea disfuncional. La afectación de la médula ósea supone la alteración de una o varias estirpes de grupos celulares como son los Hematíes, Leucocitos y Plaquetas.

En el campo de la hematología ha habido importantes avances en lo respectivo al método de obtención de médula ósea, la cual años atrás se obtenía con una punción directa sobre la cresta iliaca antero superior. Sin embargo, el desarrollo de técnicas terapéuticas ha llevado a considerar otras fuentes y formas de obtención de Células Madres Hematopoyéticas (CMH).

La existencia del Antígeno Leucocitario Humano hace imprescindible la compatibilidad entre donante-receptor, es desde luego un factor limitante cuando se trata de encontrar un donante compatible para un receptor. La búsqueda de los donantes se ha visto facilitada por la creación en 1991, del Registro Mundial de Donantes de Médula (REDMO).

La efectividad del Trasplante de Progenitores Hematopoyéticos (TPH), está determinada por factores vinculados al estado actual en el que se encuentra el paciente, fisiológica y psicológicamente, así como por un plan de cuidados específico.

Palabras clave: Trasplante de progenitores hematopoyéticos, Médula ósea, Antígeno Leucocitario Humano, Sangre periférica, sangre de cordón umbilical.

\section{ABSTRACT}

Hematopoietic Stem Cell Transplantation (HSCT) is a therapeutic modality for a group of pathologies of a hematological nature. These pathologies result in a dysfunctional bone marrow. The condition of the bone marrow involves the alteration of one or more strains of cell groups such as red blood cells, leukocytes and platelets.

In the field of hematology there has been important advances in the bone marrow obtaining method; which years ago was obtained with a direct puncture on the upper anterior iliac crest. However the development of therapeutic techniques has led to consider other sources and ways of obtaining Hematopoietic Stem Cells (HSC).

The existence of the Human Leukocyte Antigen makes compatibility between donor-recipient essential; it is of course a limiting factor when it comes to finding a compatible donor for a recipient. The search for donors has been facilitated by the creation in 1991 of Bone Marrow Donor Registry (REDMO).

The effectiveness of Stem Cell Transplantation (SCT) is determined by factors linked to the patient's physiological and psychological state, as well as by a specific care plan.

Key words: Hematopoietic Stem Cell Transplantation, Bone marrow, Human Leukocyte Antigen, Peripheral blood, umbilical cord blood. 


\section{INTRODUCCIÓN}

El concepto de Trasplante de Médula Ósea tiene sus orígenes en el siglo XIX con Artur Pappenheim, quien expone la existencia de una estirpe celular indiferenciada que madura a grupos celulares específicos y diferenciados. Es decir, que de dicha célula no diferenciada parten los otros grupos celulares. En los años 50, demostró que una médula ósea animal disfuncional por causas radioactivas podía recuperar su función hematopoyética tras infusiones de médula, A posteriori se demostró que era debido a la capacidad de las células hematopoyéticas del donante de colonizar la MO del receptor (Crespo-Fernández, 2016).

En los ensayos realizados por E. Donall Thomas en 1957 con un grupo de seis pacientes que padecían enfermedades neoplásicas medulares, aunque con pobres resultados, se pudo demostrar que importantes cantidades de MO podían ser trasfundidas por vía endovenosa (Crespo-Fernández, 2016). Sin embargo, Thomas es considerado el precursor del trasplante de progenitores hematopoyéticos y continúo con sus estudios que lo llevaron a ganar el premio nobel en 1992. A finales de los años 70, Thomas y su equipo publicaron un estudio realizado con 100 paciente pero, en esta ocasión, fueron sometidos a tratamiento con radioterapia y agentes alquilantes. Posteriormente, recibieron trasplante alogénico de un hermano HLA idéntico. En varios de los casos tratados por Thomas, la Leucemia Aguda (LA) remitió por completo (ASH, 2017; Ruiz-Argüelles, Gómez-Almague, 2013).

Tabla 1. Principales avances en el trasplante de progenitores hematopoyéticos

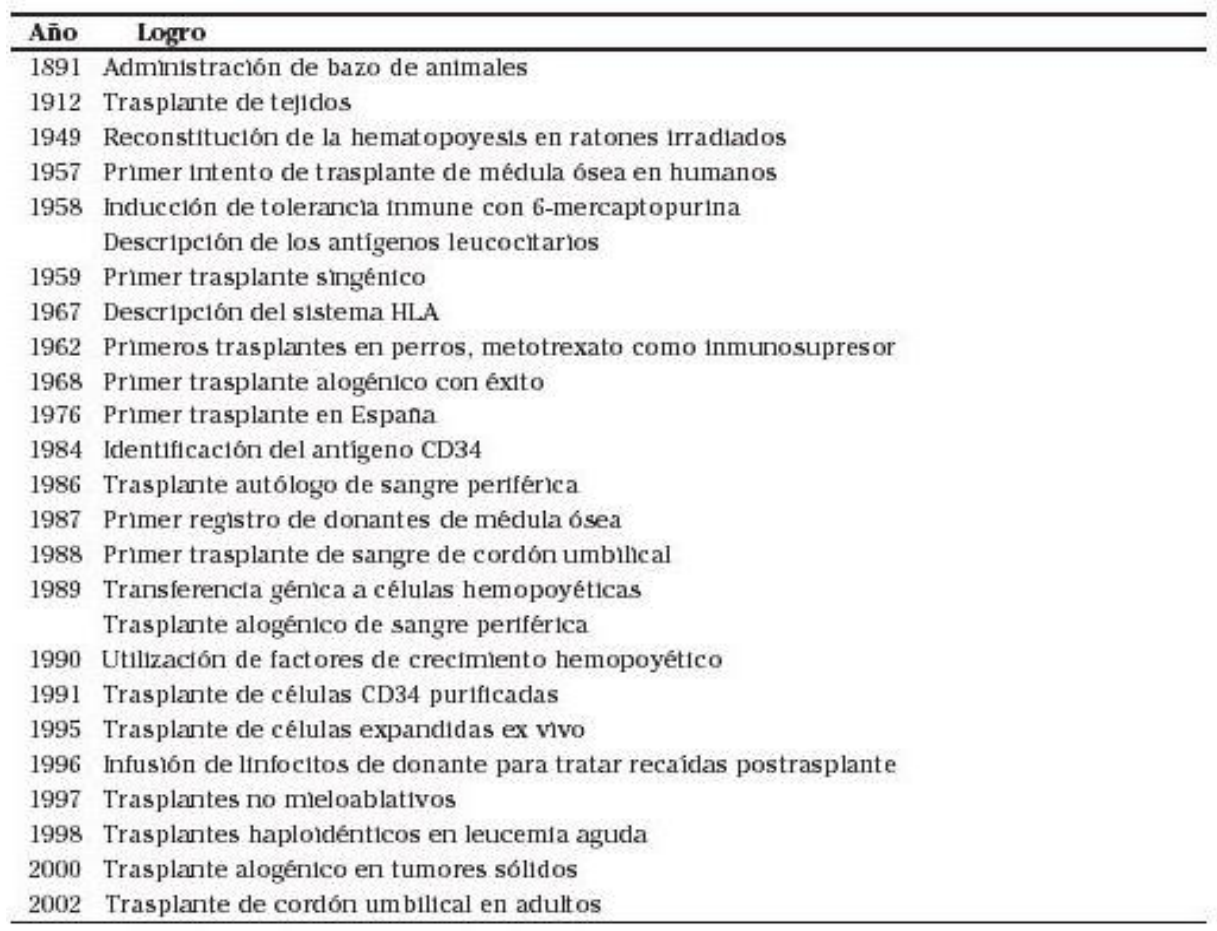

Tabla 1.Transplante de progenitores hematopoyéticos. Elaborado por Rifón, J. J. (2011) 
La médula ósea es un tejido flexible y esponjoso que se localiza en el interior de los huesos. Una MO funcional tiene capacidad hematopoyética, es decir, puede producir células hematopoyéticas pluripotenciales que posteriormente se diferenciaran a los distintos grupos celulares por ejemplo, glóbulos blancos, glóbulos rojos y plaquetas. Es pues la MO un órgano hematopoyético (ONT, 2018).

Las principales hemopatías que pueden ser tratadas mediante TPH son las Leucemias en sus variantes mieloides y linfoides, tanto crónicas como agudas. La leucemia es un cáncer de la sangre y se caracteriza por un aumento incontrolado de los leucocitos de la misma, esta hemopatía se clasifica dependiendo del tipo de células afectadas. Por lo general, la mayoría de las leucemias, incluidas sus distintas variables, requieren un TPH (ONT, 2018; Young, Weisdorf, 2016).

El linfoma es una patología que se caracteriza por una proliferación descontrolada de los linfocitos, células que pueden afectar cualquier tejido ya que se encuentran en todos los órganos. En caso de que la médula ósea se vea afectada, producirá alteraciones en la función hematopoyética (Fundación Josep Carreras, 2018).

El mieloma múltiple (MM), es otra enfermedad que afecta la $\mathrm{MO}$, caracterizada por la producción progresiva de anticuerpos. El mieloma múltiple aparece frecuentemente en personas mayores de 50 años y se le atribuyen aproximadamente el $10 \%$ de los cánceres de carácter hematológico. Las posibilidades de curación de un paciente afectado por un Mieloma múltiple dependerán del locus de la enfermedad (Fundación Josep Carreras, 2018).

Las anteriores hemopatías tienen como tratamiento base el TPH. Sin embargo, el trasplante de Progenitores es un proceso complejo, por la diversidad de factores vinculados al tratamiento y desde luego al paciente. Un TPH consiste en la infusión de células madre hematopoyéticas, después de la eliminación de la hemopoyesis del receptor, con el objetivo de que las células madre del donante germinen en la médula del receptor, restableciendo así la actividad hematopoyética (Rifón, 2006). Diversos factores como la compatibilidad HLA entre donante y receptor, el estado físico y psicológico, la administración de terapia de acondicionamiento para mejorar las posibilidades de efectividad del trasplante, condicionan los resultados finales sobre la salud del paciente (Sanchez-Salinas, 2003).

En el caso del TPH el pilar de eficacia del proceso viene determinado, básicamente por el tipo de trasplante, ya sea autólogo o alogénico. En el caso del trasplante autólogo el objetivo es la eliminación total de las células malignas, mediante quimioterapia, sin descartar la necesidad de complementar el proceso mieloablativo con radioterapia. Por lo general, este tipo de trasplante no conlleva complicaciones clínicas graves, aunque si es cierto que existe un vínculo directo con el índice de recaídas en el estado de enfermedad hematológica de base. Por otra parte, en el trasplante alogénico se persigue la eliminación celular máxima, que incremente las posibilidades de efectividad del trasplante (Ispizua, Carreras-Pons, 2016; Karp, 2011). 


\section{OBJETIVOS DEL TRABAJO}

El objetivo general de este trabajo es:

$>$ Describir los grandes aspectos que rodean el proceso de trasplante de progenitores hematopoyéticos.

Los objetivos específicos o secundarios son:

$>$ Describir los tipos de trasplante según el donante

$>$ Identificar las situaciones en las que se puede requerir un TPH

$>$ Detallar las fuentes de obtención de $\mathrm{PH}$

$>$ Exponer las complicaciones que se pueden dan en un proceso de trasplante

$>$ Identificar los cuidados enfermeros utilizando los lenguajes enfermeros estandarizados.

\section{MOTIVO DE ELECCIÓN DEL TEMA}

Durante el segundo curso de carrera en la asignatura de enfermería clínica, disfruté de la parte de la asignatura que correspondía a alteraciones hematológicas, me resultó bastante interesante. Dos años más tarde, tuve la oportunidad de rotar seis semanas de prácticas en la unidad de hematología, donde pude ampliar mis conocimientos y conocer las distintas patologías hematológicas en un primer plano, así como todo el entorno que rodea al paciente hematológico.

Pude constatar de primera mano, el gran trabajo que desempeña el equipo de enfermería y las ganas de querer contribuir al cuidado de las personas con características y situaciones tan especiales en las que se encontraban. El hecho de poder compartir con las personas las expectativas sobre los tratamientos era mas que satisfactorio, los deseos verbalizados de querer vivir y salir de esa habitación, fueron la gran motivación para querer elegir el trasplante de progenitores hematopoyéticos como tema de este trabajo.

\section{METODOLOGÍA}

Para obtener la bibliografía necesaria para la realización de este trabajo, he realizado una búsqueda con las palabras claves antes mencionadas en diferentes bases de datos como PubMed, Google académico, Scielo, Dialnet o CUIDEN.

La mayor parte de la búsqueda se ha realizado en libros digitalizados recomendados por el equipo de hematología del Hospital Universitario Marqués de Valdecilla (HUMV). También he encontrado artículos de distintas revistas en inglés.

Para ello, me ha resultado de mucha utilidad los booleanos "AND" y "OR" y especialmente, los descriptores en ciencias de la salud, médula ósea, enfermedades de médula ósea, trasplante de médula ósea y sus respectivas traducciones en lengua inglesa (MeSH). 


\section{CAPÍTULOS}

\subsection{TRASPLANTE DE PROGENITORES HEMATOPOYÉTICOS}

\subsubsection{Definición y objetivo terapéutico}

Los progenitores hematopoyéticos son un grupo de células que se localizan en la médula ósea y en menor medida en sangre periférica. Estas células se encuentran en un estado indiferenciado. En lengua vernácula, los progenitores hematopoyéticos son también llamados células madre, ya que son estas las que dan origen a todas las células del organismo. Por lo tanto, el proceso de hematopoyesis se lleva a cabo en la médula ósea (Ispizua, Carreras-Pons, 2016; ONT, 2018; Sánchez-Salinas, 2003).

Durante el proceso hematopoyético las células toman dos rutas de diferenciación celular. Una de ellas es la línea linfoide, que llevará a la producción de linfocitos T y B. La segunda opción posible es la ruta mieloide, la cual resultará en los procesos de trombopoyesis (plaquetas), eritropoyesis (hematíes), granulopoyesis (eosinófilos, basófilos, neutrófilos), monocitopoyesis (monocitos) (Ispizua, Carreras-Pons, 2016; ONT, 2018).

Figura 1: Hematopoyesis

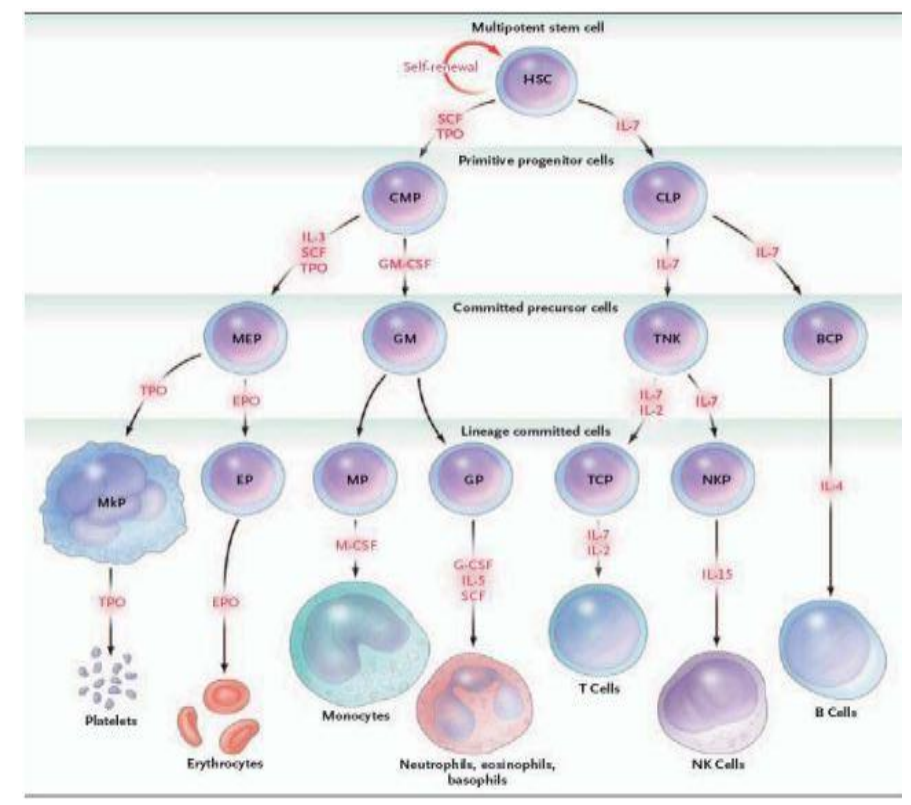

Figura 1. Thrombopoietin. Elaborada por Kaushansky K. (1998) 
La importancia del TPH radica en la capacidad de las células madre hematopoyéticas pluripotenciales para restablecer la función medular, originando leucocitos, eritrocitos, y trombocitos. Por esta razón, el objetivo terapéutico de TPH es el tratamiento de neoplasias o alteraciones de la médula, trastornos del sistema inmunitario y alteraciones metabólicas congénitas (Ispizua, Carreras-Pons, 2016; ONT, 2018).

\subsubsection{Tipos de trasplante según la relación donante-receptor}

El trasplante de órganos y tejidos representa uno de los mayores avances en el desarrollo de la medicina. Actualmente, es una práctica cada vez más habitual en los países desarrollados. Los avances en el trasplante de órganos y tejidos se han visto marcados por el progreso en las técnicas médicas, inmunología y farmacología. Un trasplante consiste en reemplazar un órgano o tejido disfuncional por uno sano. De manera que, los trasplantes representan una esperanza para afecciones en las cuales los tratamientos farmacológicos y quirúrgicos, no son una opción (Rifón, 2006).

Es imperativo resaltar el papel que desempeñan los donantes, ya que la donación de órganos y tejidos es una acción voluntaria.

Atendiendo a la relación donante-receptor, existen tres tipos básicos de trasplante:

Trasplante autólogo o autotransplante: en este tipo de trasplante, las células a trasplantar provienen directamente del paciente enfermo. Se extraen células madre de la médula del paciente, posteriormente se le administran altas dosis de quimioterapia con o sin radioterapia (proceso de ablación), para finalmente efectuar el trasplante de sus propias células (Karp, 2011; Rifón, 2006; VidalManceñido, 2011).

Trasplante singénico o isotrasplante: la característica que destaca este tipo de trasplante, es la presencia de un donante genéticamente idéntico, en este caso un gemelo, o trillizo. En este tipo de trasplante el factor de riesgo representado por la EICH no existiría, como tampoco la posibilidad presencia de células cancerígenas, como es el caso del trasplante autólogo (Rifón, 2006; VidalManceñido, 2011).

Trasplante alogénico o alotrasplante: en esta modalidad de trasplante el paciente recibe los progenitores hematopoyéticos que provienen de un donante, el cual, puede ser un hermano o familiar, en cuyo caso, se denomina trasplante alogénico emparentado. Otra posibilidad es que el donante no tenga ningún parentesco familiar con el receptor, y se denomina trasplante alogénico no emparentado. En las dos situaciones mencionadas, el donante no es genéticamente igual al receptor, pero si similar, siendo ese grado de similitud el que determinará las posibilidades de compatibilidad donante-receptor (Karp, 2011; Rifón, 2006; Vidal-Manceñido, 2011). 


\subsubsection{Indicaciones y contraindicaciones del TPH}

Para el tratamiento de ciertas enfermedades de la sangre, se requiere la eliminación de las células anómalas o cancerígenas del organismo. Esto se consigue mediante la administración de altas dosis de quimioterapia y en ocasiones también con radioterapia (Young, Weisdorf, 2016). La administración de tratamiento mieloablativo no destruye solo las células anormales, sino también las sanas, un estado que es totalmente incompatible con la vida del individuo. Por esta razón se realiza un trasplante de células madre o progenitores hematopoyéticos, cuya función es reestablecer la función medular normal del paciente trasplantado (Burgaleta-Alonso, Fernández-Jurado, García-Frade, et al., 2010; Fundación Josep Carreras, 2018; Rifón, 2006).

Las indicaciones más comunes del TPH son las leucemias agudas, la leucemia mieloide crónica (LMC), anemia aplásica y determinadas alteraciones congénitas de carácter inmunodeficiente. No obstante, con el paso del tiempo, y los avances médicos, el margen de indicación terapéutico del TPH, incluye otras patologías como el mieloma múltiple (MM), Síndrome mielodisplásico, Enfermedad de Hodgkin y el linfoma (Ispizua, Carreras-Pons, 2016; Rifón, 2006).

Tabla 2. Relación patología/tipo de trasplante

\begin{tabular}{|c|c|c|}
\hline AUTÓLOGO & SINGÉNICO & ALOGÉNICO \\
\hline LMA & $\begin{array}{l}\text { De elección antes } \\
\text { de un trasplante } \\
\text { alogénico }\end{array}$ & $\begin{array}{l}\text { LMA en pacientes de alto riesgo, } \\
\text { resistente, recaidas y secundarias }\end{array}$ \\
\hline LLA (muy restringido) & & $\begin{array}{l}\text { ¿LA en } 1 \text { a remisión completa, } \\
\text { pacientes muy alto riesgo, } \\
\text { refractarios o recaídas) }\end{array}$ \\
\hline$M M+$ quimioterapia & & $\begin{array}{c}\text { LMC en pacientes que no } \\
\text { responden al Imatinib (inhibidor de } \\
\text { la tirosina quinasa), fase acelerada } \\
\text { o crisis blástica }\end{array}$ \\
\hline $\begin{array}{l}\text { LNH con enfermedad refractaria y } \\
\text { recaida }\end{array}$ & & LLC en pacientes alto riesgo \\
\hline LH en recaída quimio sensible & & MM con mal pronóstico \\
\hline $\begin{array}{c}\text { Otros: aplasia medular en pacientes } \\
\text { graves y jóvenes. } \\
\text { Inmunodeficiencias, trastornos } \\
\text { autoinmunes y algún tumor solido } \\
\text { bajoensayo clínico }\end{array}$ & & Otros: trastornos congénitos \\
\hline
\end{tabular}

Tabla 2: Transplante de progenitores hematopoyéticos. Elaborada por Silvia Crespo a partir de S. Fauci A, L. Longo D, L. Kasper D, Braunwald E, Jameson L, Loscalzo J L. Hauser Stephen. Harrison. (2016) 


\subsection{PROCESO DE DONACIÓN}

El proceso de TPH puede requerir la donación por parte de un donante emparentado o no emparentado, lo que determinará el tipo de trasplante. Así mismo, se incluye el proceso de obtención y almacenamiento de las $\mathrm{CMH}$, terapia de acondicionamiento y proceso de infusión de las mismas (Ispizua, Carreras-Pons, 2016; Young, Weisdorf, 2016).

\subsubsection{El donante de células hematopoyéticas}

De forma tradicional, se ha dicho que toda persona puede convertirse en donante de médula, siempre y cuando tenga un buen estado de salud que no implique riesgo para el donante o el receptor, y una edad entre 18 y 55 años. Tras varios estudios y observaciones a lo largo de los años, se ha demostrado que la edad del receptor guarda un vínculo directo con la efectividad del trasplante. Por lo anterior, hoy se intenta reducir el límite superior de edad a 40 años (Fundación Josep Carreras, 2019).

En el momento en el que una persona decide ser donante de médula, facilitará sus datos personales, además de su historial clínico. Como parte del proceso de inclusión en la Red de Donantes de Médula (REDMO) se asigna un código único para cada donante. También se extrae una muestra de sangre o de saliva con el objetivo de determinar las características de histocompatibilidad. El donante debe dar su consentimiento para que sus datos personales y características de compatibilidad sean introducidos en la REDMO, que a su vez los proporcionará a la Red Mundial de Donantes de Médula (Bashir, Champlin, 2014; Fundación Josep Carreras, 2018; Kohn, Notarangelo, 2016).

\subsubsection{Marco legal de la donación}

Es importante mencionar que toda donación de órganos y tejidos debe cumplir la normativa establecida en el Real Decreto Ley 9/2014, en el cual se establece la regulación de la donación y trasplante de órganos y tejidos humanos (Fundación Josep Carreras, 2018). Las características más relevantes de esta normativa son (Blanes-Juliá, Gómez-Busto, GiménezMartí, et al. 2011; Pérez-Fernández, 2016):

- Confidencialidad: en ningún momento se divulgarán las identidades del donante o del receptor.

- Gratuidad: el objetivo de la donación de progenitores hematopoyéticos en ningún momento se hará con ánimo de lucro, por lo que no se exigirá retribución económica o beneficio alguno por parte o a favor del donante.

- Finalidad terapéutica: la donación de progenitores hematopoyéticos solo podrá tener como objetivo final la aplicación terapéutica.

- Obtención de progenitores hematopoyéticos: en lo que respecta a la obtención de los $\mathrm{CPH}$, deberá realizarse en centros debidamente autorizados. Para ello, la ubicación geográfica de estos centros deberá ser la más cercana y 
accesible al domicilio del donante (Fundación Josep Carreras, 2019) (CrespoFernández, 2016).

\subsubsection{Obtención de los progenitores hematopoyéticos}

Los factores de inmunidad y hematopoyesis vienen derivados de los progenitores hematopoyéticos del donante. Las células madre se caracterizan por tener en la superficie el complejo de diferenciación 34 (CD34+). Este marcador ayuda a diferenciar las células madre, así como a determinar la cantidad de estas, ya sea en sangre periférica o medula ósea (Fundación Josep Carreras, 2018; Rifón, 2006; Sancho, Duarte, Medina, et al., 2016).

La principal fuente de obtención de progenitores había sido la medula ósea. A través de múltiples punciones bajo anestesia general se obtenía el material celular. Pero, las células hematopoyéticas también se encuentran circulantes en la sangre periférica, en este caso para su extracción, se requiere la administración de factores de crecimiento de granulocitos para aumentar la concentración de estas células en sangre, y así disponer de una mayor cantidad de células en SP que puede ser extraídas (Fundación Josep Carreras, 2018; Sancho, Duarte, Medina, et al., 2016). Así, la cantidad de células madre extraídas de sangre periférica son incluso superiores a las que pueden ser obtenidas mediante aspiración medular (Rifón, 2006).

De manera que las células progenitoras pueden obtenerse mediante una punción directa en la médula ósea o el cordón umbilical o por medio de aféresis. Estos procedimientos se llevan a cabo dependiendo de la fuente de PH:

- A partir de médula ósea: la extracción de medula ósea se realiza bajo anestesia general en el quirófano. La zona más común de punción es la cresta iliaca anterosuperior. El donante permanece en el hospital para la recuperación postanestesica y control del dolor agudo. Por lo general. En el transcurso de una semana suelen recuperar la normalidad en las actividades de la vida diaria (Ispizua, Carreras-Pons, 2016; Rifón, 2006).

- A partir de sangre periférica: también llamada sangre circulante, hoy en día es la principal fuente de células madre. Las células hematopoyéticas presentes en la sangre circulante provienen de la medula ósea. Con la obtención de estas mediante el procedimiento de aféresis, se extraen cuerpos celulares concretos en lugar de todo el conglomerado sanguíneo (Patterson, Winters, 2012). Para el proceso de aféresis no se requiere anestesia, por lo que desaparecen los riesgos vinculados a la anestesia general, ni son necesarias las punciones en el hueso iliaco, y por tanto no habrá el dolor derivado de la intervención (Fundación Josep Carreras, 2018; Rifón, 2006).

La médula ósea solo libera una minúscula cantidad de células madre a la sangre circulante, por lo que es necesaria la administración de factores de crecimiento y movilización para incrementar el paso de estas células a la sangre periférica y así disponer de una mayor cantidad de estas para su extracción (Guzmán-Sánchez, 2014; ONT, 2018) 
- A partir de Sangre de cordón umbilical: la sangre de cordón umbilical en adelante SCU, contiene gran cantidad de células madre hematopoyéticas, las cuales tienen la capacidad de restaurar las células sanguíneas (Maestud-Martín, G. et al., 2015). El tejido sanguíneo que permanece en el cordón umbilical después del nacimiento es muy rico en progenitores hematopoyéticos capaces de desencadenar la reconstitución de la MO (Scaradavou, 2018). Estás células tienen la misma capacidad que las células extraídas de la medula ósea de una persona adulta (Aronson, 2016; Rifón, 2006).

En hematopatías que afectan la médula ósea, el trasplante de SCU permite la generación de nuevas células sanguíneas. Las células procedentes de sangre de cordón tienen características especiales como su capacidad de diseminación e inmadurez, lo cual lleva a no requerir un porcentaje de compatibilidad tan elevado como en los trasplantes provenientes de medula ósea, esto se traduce en una menor posibilidad de rechazo del implante (Aronson, 2016; Maestud-Martín, G. et al., 2015; Rifón, 2006).

\subsubsection{Extracción y procesamiento del material celular}

Como se ha mencionado en los capítulos anteriores, los $\mathrm{PH}$, se pueden obtener de la médula ósea mediante una punción en el hueso iliaco, bajo anestesia general, también de la sangre periférica mediante el proceso de citoaféresis o del cordón umbilical. Una vez extraídas las $\mathrm{CPH}$, estas deben ser transportadas al lugar idóneo para su procesamiento (Sánchez-Salinas, 2003).

Para que las células obtenidas conserven su funcionalidad fisiológica, deben ser almacenadas en recipientes adaptados para su transporte y monitorización térmica (CrespoFernández, 2016).

Con los instrumentos tecnológicos con los que se cuenta en la actualidad, tras una extracción, se obtiene el volumen idóneo de producto. Sin embargo, muchas veces este volumen es muy superior al que se requiere, por esta razón el material obtenido tras la donación se somete a un proceso de centrifugado, con el objetivo de separar el plasma, la población leucocitaria y los hematíes, y posteriormente se desecha el volumen plasmático sobrante. Tras este proceso se logra el volumen adecuado para la infusión sin alterar la concentración de CPH presentes en el producto final (Crespo-Fernández, 2016; Young, Weisdorf, 2016).

Una vez extraídos, los progenitores hematopoyéticos pueden trasplantarse en fresco, o ser sometidos al proceso mencionado en el párrafo anterior, que también incluirá criopreservación, empaquetado y correcto etiquetado para quedar finalmente preparado para ser infundido al paciente. El objetivo de la criopreservación es mantener la funcionalidad celular del material obtenido hasta la infusión al receptor (Crespo-Fernández, 2016).

Es importante la velocidad de congelación, ya que el propio proceso de crioconservación puede provocar destrucción celular. La temperatura de conservación es de -196C. 
utilizando como medio el nitrógeno líquido. Durante el crioprocesamiento se utilizan factores penetrantes y no penetrantes, el más utilizado es el DMSO, el cual impide la formación de cristales a nivel intracelular, evitando la destrucción de las células a trasplantar (Sánchez-Salinas, 2003; Scaradavou, 2018).

Los componentes restantes, son prótidos y un anticoagulante, que impedirá la coagulación durante el procesamiento de congelación y descongelación.

En el supuesto de que se decida una infusión en fresco, esta ha de realizarse en un plazo de 72 horas (BSTC, 2017).

\subsubsection{Preparación del receptor}

Antes de la infusión de las células madre del donante, el receptor debe someterse a lo que se denomina proceso de acondicionamiento, el cual consiste en la administración de quimioterapia con o sin radioterapia (Rifón, 2006). El proceso de acondicionamiento persigue tres objetivos que son, crear un espacio de alojamiento para las células del donante, la supresión inmunológica para reducir el riesgo de EICH y por último la eliminación de las células tumorales. Cuando la terapia de acondicionamiento tiene la suficiente intensidad para inmunodeprimir al paciente, se denomina trasplante mieloablativo, sin embargo, cuando la intensidad del tratamiento de acondicionamiento no consigue una inmunosupresión total, se habla de un trasplante no mieloablativo (Ispizua, Carreras-Pons, 2016; Sánchez-Salinas, 2003; Young, Weisdorf, 2016).

\subsubsection{Complicaciones del proceso de trasplante}

Durante el proceso de trasplante se pueden dar distintas y variadas complicaciones, las cuales dependen de diversos factores como la enfermedad de base y el estadio de la misma, la condición del paciente o el proceso de acondicionamiento atendiendo a su intensidad (Holgado-Pérez, 2015; Karp, 2011; Rifón, 2006).

Las complicaciones con mayor incidencia son aquellas relacionadas con el régimen de acondicionamiento, tales como:

- Toxicidad gastrointestinal: la cual provoca mucositis, esofagitis, gastroenteritis, pancreatitis, en su mayoría como resultado de la los citostáticos a dosis altas (Rifón, 2006).

- Toxicidad renal y de las vías urinarias: muchos de los fármacos o sus metabolitos empleados en la terapia de acondicionamiento se eliminan total o parcialmente por vía renal, lo que expone al sistema urinario en su conjunto a lesiones en cualquiera de sus estructuras. Cobra aquí gran importancia la adecuada terapia de hidratación para la protección renal y facilitar la eliminación, además de un exhaustivo control de las dosis de los fármacos utilizados con respecto al grado de función de renal del paciente (Rifón, 2006). 
Los fármacos como el cisplatino y el metrotexato suelen ser los más vinculados a procesos de insuficiencia renal leve, situación que es reversible. Sin embargo, el uso a dosis altas de metrotexato conlleva insuficiencia renal grave, que en determinado momento puede requerir diálisis (Rifón, 2006).

En ocasiones el empleo de QT produce daño del tejido de la vejiga, la cistitis hemorrágica aparece con frecuencia en pacientes en cuyo tratamiento se encuentra la ciclofosfamida (Ispizua, Carreras-Pons, 2016). En los casos de cistitis hemorrágicas los pacientes presentan disuria, espasmos y hematuria (SEOM, 2013).

- Enfermedad veno-oclusiva hepática: se produce por una proliferación del tejido endotelial a causa de la toxicidad hepática por la administración del tratamiento de acondicionamiento previo y posterior al TPH (Carreras, 2015). Es una complicación que tiene lugar entre los 14 y 20 días posteriores al inicio del tratamiento por el estrechamiento de las vénulas hepáticas y necrosamiento de los hepatocitos ocasionado por el proceso de acondicionamiento (Ispizua, Carreras-Pons, 2016). Esta complicación se caracteriza por una hepatomegalia dolorosa, retención de líquidos e ictericia. Existe una relación directa entre el régimen terapéutico utilizado y la aparición del SOSH, disminuyendo su aparición en los tratamientos no mieloablativo o con la administración de fármacos como busulfán por vía IV (Carreras, 2015; Holgado-Pérez, 2015; Rifón, 2006).

- Infecciones: representan una de las complicaciones más importante pre y post trasplante de progenitores, son el resultado del estado de neutropenia y la lesión de la mucosa, provocado por la terapia de acondicionamiento. Una importante granulocitopenia hace que la susceptibilidad del paciente a las infecciones aumente, por ejemplo las bacterianas, por Cándida albicans. En ocasiones presentan infecciones por Herpes y CMV, en el primer trimestre post-trasplante (Blanes-Juliá, Gómez-Busto, Giménez-Martí, et al. 2011; Rifón, 2006; Rovira, y Ruiz-camps, 2017).

- Hemorragias: la terapia de acondicionamiento induce un estado de trombocitopenia, dicho estado promueve la presencia de hemorragias. Las hemorragias representan una complicación importante, para evitarlas se llevan a cabo transfusiones de plaquetas como medida de profilaxis utilizando sangre periférica. Para evitar casos de rechazo en el proceso de infusión se someten a irradiación (Ispizua, Carreras-Pons, 2016; Rifón, 2006).

- Fallo del injerto: esta complicación se presenta cada vez con menos frecuencia. No obstante, en ocasiones el paciente no recupera la adecuada función hematopoyética, lo que se denomina fallo primario, o secundario en situaciones en las que pierde dicha función tras un periodo inicial de recuperación hematopoyética (Ispizua, Carreras-Pons, 2016; ONT, 2018; Rifón, 2006). 
- Enfermedad de injerto contra el huésped (EICH): es una de las mayores y más frecuentes complicaciones que pueden surgir en un TPH. En el momento en el que se realiza un trasplante, el huésped adopta una situación de quimera, es decir, porta en su organismo células de dos individuos. La EICH puede clasificarse atendiendo a patrones de intensidad en grave, moderada o leve, y según el tiempo de aparición de signos y síntomas en aguda o crónica. De forma convencional la fase aguda se presenta en los primeros 100 días post trasplante (López-Granados, Torres-Cañizales, 2015; Rifón, 2006; Vidal-Manceñido, 2011).

En la EICH existe una reacción inmune por parte de las células trasplantadas del donante, contra las células del receptor, con la consecuente liberación de citoquinas que hacen blanco a órganos diana (Velardi, Localleti, 2016). Desde un punto de vista biológico, es la respuesta normal de un sistema inmunitario, a pesar de representar riesgo para vida del paciente. Cuando se hace referencia a un alotrasplante, viene implícito el riesgo de EICH pese a la utilización del donante más adecuado, y la administración de tratamiento inmunosupresor en los periodos previos y posteriores a la infusión de CH (Karp, 2011; VidalManceñido, 2011; Young, Weisdorf, 2016).

\subsection{ASPECTOS EMOCIONALES DEL PACIENTE CON TPH}

Tanto el diagnostico de una patología de carácter oncohematológico como su tratamiento, supone un evento de estrés para el paciente, no solo por el significado de cáncer, sino también por las perspectivas relacionadas con el tratamiento el cual se percibe claramente como sufrimiento por las intervenciones médicas que conlleva (Linares, Moratalla, Romero, et al. 2007).

Sin embargo, los pacientes sometidos a un TPH valoran de forma positiva el proceso, teniendo en cuenta los beneficios, la complejidad y el esfuerzo a nivel de recursos humanos y económicos que se despliegan a su alrededor (García, Mumby, Thilges, et al., 2012). La enfermedad y su tratamiento requieren que el paciente se introduzca en un contexto de variabilidad emocional, donde variables niveles de ansiedad, ira, depresión y trastornos del sueño están a flor de piel. Un entorno potenciado además por el desconocimiento de las técnicas médicas y la administración de fármacos de forma continuada (Ascencio, 2011).

A grandes rasgos, los pacientes con patologías oncológicas se encuentran bajo estrés y ansiedad generados por la visión de una posible muerte, alteración de la imagen corporal, efectos del tratamiento sobre su rol social, la alteración de su proyecto de vida y la visión de cómo será su situación social post trasplante (Bieri, Roosnek, Helg, 2008). 


\subsection{PLAN DE CUIDADOS ESTANDARIZADO DE ENFERMERÍA}

Para la elaboración del mismo se ha seguido el modelo bifocal de Lynda Carpenito que diferencia diagnósticos enfermeros y complicaciones potenciales. Y para la definición de los diagnósticos, resultados e intervenciones enfermeras se han utilizado los lenguajes enfermeros estandarizados NANDA-I (Herdman y Kamitsuru, 2015), Nursing Outcomes Classification (NOC) (Moorhead, Johnson, Mass et al., 2013) y Nursing Interventions Classificaction (NIC) (Bulechek, Butcher, Dochterman et al., 2013).

A continuación, se expone un plan de cuidados de enfermería estandarizado de un paciente sometido a trasplante de progenitores hematopoyéticos teniendo en cuenta las características de este procedimiento expuestos anteriormente. El tiempo en el que está basado son los primeros 15-20 días post trasplante.

Este plan de cuidados podrá variar tanto como la situación individual de cada paciente y las circunstancias ligados a los procesos del mismo.

\section{DIAGNÓSTICOS ENFERMEROS}

NANDA-I: Conocimientos deficientes (00126):

Carencia o deficiencia de información cognitiva relacionada con un tema específico

Factores relacionados:

Información insuficiente

Características definitorias:

Conocimiento insuficiente

\begin{tabular}{|c|c|}
\hline $\begin{array}{l}\text { NOC: Conocimiento: proceso de la enfermedad (1803) } \\
\text { Grado de conocimiento transmitido sobre el proceso de una enf } \\
\text { complicaciones potenciales }\end{array}$ & ermedad concreta y las \\
\hline Indicadores & Escala u \\
\hline $\begin{array}{l}\text { [180302] Características de la enfermedad } \\
\text { [180306] Signos y síntomas de la enfermedad } \\
\text { [180307] Curso habitual de la enfermedad } \\
\text { [180309] Complicaciones potenciales de la enfermedad } \\
\text { [180313] Efecto psicosocial de la enfermedad sobre uno mismo } \\
\text { [180314] Efecto psicosocial de la enfermedad sobre la familia } \\
\text { [180317] Fuentes acreditadas de información sobre la } \\
\text { enfermedad específica }\end{array}$ & $\begin{array}{l}\text { 1. Ningún conocimiento } \\
\text { 2. Conocimiento escaso } \\
\text { 3. Conocimiento moderado } \\
\text { 4. Conocimiento sustancial } \\
\text { 5. Conocimiento extenso }\end{array}$ \\
\hline
\end{tabular}


NOC: Conocimiento: régimen terapéutico (1813)

Grado de conocimiento transmitido sobre el régimen terapéutico específico

Indicadores

[181301] Beneficios del tratamiento

[181304] Efectos esperados del tratamiento

[181309] Procedimientos prescritos

[181316] Beneficios del control de la enfermedad

Escala u

1. Ningún conocimiento

2. Conocimiento escaso

3. Conocimiento moderado

4. Conocimiento sustancial

5. Conocimiento extenso

NOC: Conocimientos: medicación (1808)

Grado de conocimiento transmitido sobre el uso seguro de la medicación

\begin{tabular}{|l|l|}
\hline Indicadores & Escala u
\end{tabular}

[180802] Nombre correcto de la medicación

[180805] Efectos secundarios de la medicación

[180810] Uso correcto de la medicación prescrita

[180819] Efectos terapéuticos de la medicación

1. Ningún conocimiento

2. Conocimiento escaso

3. Conocimiento moderado

4. Conocimiento sustancial

5. Conocimiento extenso

NIC: Enseñanza: proceso de enfermedad (5602)

Ayudar al paciente a comprender la información relacionada con un proceso de enfermedad específico

Actividades:

- Evaluar el nivel actual de conocimientos del paciente relacionado con el proceso de enfermedad específico

- Describir los signos y síntomas comunes de la enfermedad, según corresponda

- Describir el proceso de la enfermedad, según corresponda

- Evitar las promesas tranquilizadoras vacías

- Proporcionar información a la familia/allegados acerca de los progresos del paciente, según proceda

- Reforzar la información suministrada por los otros miembros del equipo de cuidados, según corresponda.

\section{NIC: Enseñanza: procedimiento/tratamiento (5618)}

Preparación de un paciente para que comprenda y se prepare mentalmente para un procedimiento o tratamiento prescrito

\section{Actividades:}

- Determinar las experiencias del paciente y el nivel de conocimientos relacionados con el procedimiento tratamiento.

- Explicar el propósito del tratamiento.

- Determinar las expectativas del procedimiento/tratamiento por parte del paciente. 
- Corregir las expectativas poco realistas del procedimiento/tratamiento según corresponda.

- Dar tiempo al paciente para que haga pregunta y resuelva sus inquietudes.

- Incluir al familiar según corresponda.

NIC: Enseñanza: medicamentos prescritos (5616)

Preparar al paciente para que tome de forma segura los medicamentos prescritos y observar sus efectos

Actividades:

- Informar al paciente acerca del propósito y acción de cada medicamento Revisar el conocimiento que el paciente tiene cada medicación

- Instruir al paciente acerca de la administración/aplicación adecuada de cada medicamento Evaluar la capacidad del paciente para administrarse los medicamentos él mismo

- Informar al paciente sobre las consecuencias de no tomar o suspender bruscamente la medicación

- Instruir al paciente acerca de los posibles efectos adversos de cada medicamento Incluir a la familia/allegados, según corresponda

\section{NANDA-I: Déficit de autocuidado: baño (00108)}

Deterioro de la capacidad para realizar o completar por uno mismo las actividades de baño

Factores relacionados:

Ansiedad, debilidad, deterioro musculoesquelético

\section{Características definitorias:}

Deterioro de la habilidad para acceder al baño, deterioro de la habilidad para lavar, deterioro de la habilidad para secar el cuerpo

\begin{tabular}{|c|c|}
\hline \multicolumn{2}{|c|}{$\begin{array}{l}\text { NOC: Autocuidados: baño (0301) } \\
\text { Acciones personales para lavar el propio cuerpo independientemente con o sin dispositivo de } \\
\text { ayuda }\end{array}$} \\
\hline Indicadores & Escala a \\
\hline $\begin{array}{l}\text { [30101] Entra y sale del cuarto de baño } \\
\text { [30109] Se baña en la ducha } \\
\text { [30111] Seca el cuerpo } \\
\text { [30113] Se lava la cara } \\
\text { [30114] Se lava la parte superior del cuerpo } \\
\text { [30115] Se lava la parte inferior del cuerpo } \\
\text { [30116] Se lava la zona perianal }\end{array}$ & $\begin{array}{l}\text { 1. } \text { Gravemente comprometido } \\
\text { 2. Sustancialmente comprometido } \\
\text { 3. } \\
\text { 4. } \text { Lederadamente comprometido } \\
\text { 5. }\end{array}$ \\
\hline
\end{tabular}


NIC: Ayuda con el autocuidado: baño/higiene (1801)

Ayudar al paciente a realizar la higiene personal

Actividades:

- Colocar toallas, jabón, desodorante, equipo de afeitado y demás accesorios necesarios a la cabecera del paciente o en el baño.

- Facilitar que el paciente se bañe él mismo, según corresponda

- Proporcionar ayuda hasta que el paciente sea totalmente capaz de asumir los autocuidados

- Considerar la cultura del paciente al fomentar las actividades de autocuidado

- Considerar la edad del paciente al fomentar las actividades de autocuidado Determinar la cantidad y tipo de ayuda necesitada

- Mantener rituales higiénicos

\section{NANDA-I: Ansiedad (00146):}

Sensación vaga e intranquilizadora de malestar o amenaza acompañada de una respuesta autónoma (el origen de la cual con frecuencia es inespecífico o desconocido para la persona); sentimiento de aprensión causado por la anticipación de un peligro. Es una señal de alerta que advierte de un peligro inminente y permite a la persona tomar medidas para afrontar la amenaza.

Factores relacionados:

Amenaza al estatus habitual, factores estresantes, grandes cambios

Características definitorias:

Angustia, incertidumbre, nerviosismo, temor, cavilación, confusión, preocupación, inquietud.

NOC: Nivel de ansiedad (1211)

Gravedad de la aprensión, tensión o inquietud manifestada surgida de una fuente no identificable

\begin{tabular}{|l|l|}
\hline Indicadores & Escala $\mathbf{~}$ \\
\hline [121101] Desasosiego & 1. Grave \\
[121105] Inquietud & 2. Sustancial \\
[121116] Aprensión verbalizada & 3. Moderado \\
[121117] Ansiedad verbalizada & 4. Leve \\
\hline & 5. Ninguno \\
\hline
\end{tabular}


NIC: Disminución de la ansiedad (5820)

Minimizar la aprensión, temor, presagios o inquietud relacionados con una fuente no identificada de peligro previsto

Actividades:

- Utilizar un enfoque sereno de tranquilidad

- Proporcionar información objetiva del diagnóstico, pronostico y tratamiento

- Animar a la familia a estar con el paciente, si procede.

- Crear un ambiente que facilite la confianza y favorezca la relación terapéutica.

- Animar al paciente a manifestar sus sentimientos, percepciones, expectativas y miedos.

NANDA-I: Riesgo de cansancio del rol de cuidador (00062)

Vulnerable a tener dificultad para desempeñar el rol de cuidador de la familia o de otras personas significativas, que puede comprometer la salud.

\section{Factores de riesgo}

Actividades de cuidados excesivas, aislamiento del cuidador, complejidad de las tareas de cuidados, factores estresantes, gravedad de la enfermedad del receptor del cuidado, imprevisibilidad de la evolución de la enfermedad

NOC: Salud emocional del cuidador principal (2506)

Bienestar emocional de un cuidador familiar mientras atiende a un miembro de la familia

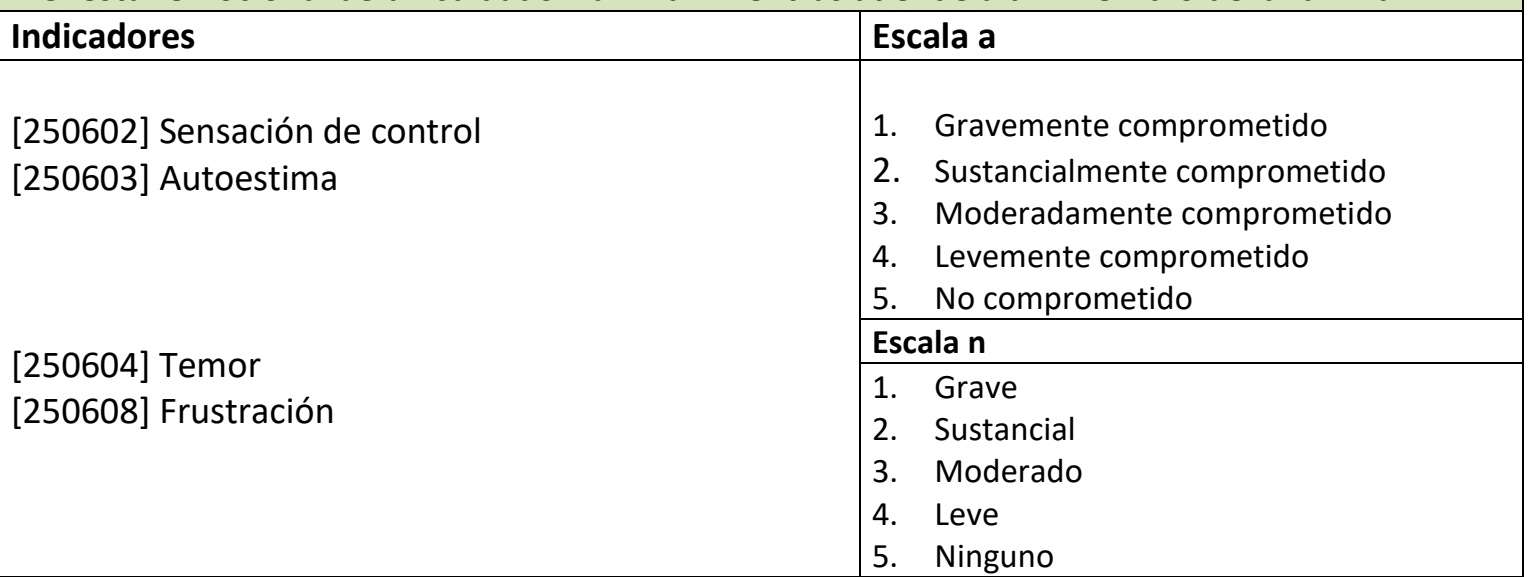

\section{NIC: Apoyo al cuidador principal (7040)}

Ofrecer la información, consejos y apoyo necesarios para facilitar que el cuidado primario del paciente lo realice una persona distinta de un profesional sanitario

\section{Actividades:}

- Determinar el grado de conocimientos del cuidador

- Determinar el nivel de aceptación de su rol de cuidador

- Analizar junto con el cuidador los puntos fuertes y débiles

- Instruir sobre técnicas de cuidado y seguridad del paciente 
- Explorar la capacidad de afrontamiento del cuidado

- Brindar refuerzo positivo al paciente al cuidador ante momentos de dificultad

\section{COMPLICACIONES POTENCIALES:}

$>$ Nauseas y/o vómitos

$>$ Dolor

Diarrea

$>$ Hemorragia

$>$ Fiebre

$>$ Mucositis

Síndrome de obstrucción sinusoidal del hígado

$>$ Infección

$>$ Desnutrición

$\underline{\text { Objetivos }}$

- Detectar signos y síntomas de inestabilidad fisiológica en lo que respecta al estado al estado actual y evolución del paciente, derivados de la enfermedad, pruebas y tratamientos.

- Prevención de complicaciones.

$\underline{\text { Intervenciones }}$

- Valoración signos y síntomas:

- Mareos

- Astenia

- Pérdida de peso

- Signos de alteración de la integridad de la mucosa oral

- Fiebre

- Rubor

- Hemorragia

- Hematoma

- Ictericia

- Analíticas de sangre: necesarias para controlar la concentración en sangre de los fármacos administrados y de los efectos en el estado de la actividad celular del paciente. Por otra parte, se requiere llevar un control exhaustivo del estado hematopoyético post trasplante.

- Administración de antieméticos en caso de vómitos.

- En situaciones de desnutrición puede ser necesario administrar nutrición parenteral. 
- Enjuagues con bicarbonato y administración de óvulos de vitamina E en caso de lesión de la mucosa oral.

- Transfusión de componentes sanguíneos según los resultados de las analíticas y valoración médica.

- Administración de antipiréticos en caso de fiebre, con extracción de hemocultivos según petición médica.

- Administración de terapia inmunosupresora para evitar fenómenos de rechazo del trasplante.

- Sueroterapia como medida de protección renal y prevención del SOSH. 


\section{BIBLIOGRAFIA}

American Society of Hematology (ASH). (2017). Legends in Hematology: E. Donnall Thomas (1920-2012). Recuperado de: http://www.hematology.org/About/History/Legends/2079.aspx

Aronson, J.K. (2016). Blood cell transfusion and bone marrow transplantation (1007-24) Meyler's Side Effects of Drugs. Amsterdam, Nederlands: Elsevier.

Ascencio-Huertas, L. (2011). Evaluación psicológica para protocolo de trasplante de células hematopoyéticas en adolescentes. Psicología y salud, 21(2), 253-63. Recuperado de: https://dialnet.unirioja.es/servlet/tesis?codigo $=58070$

Bashir, Q., \& Champlin, R. (2014) Hematopoietic Stem Cell Transplantation. En Niederhuber J. E., Armitage, J. O., \& Tepper J. E. (Ed.), Abeloff's Clinical Oncology (485-92). Amsterdam, Nederlads: Elsevier.

Banco de Sangre y Tejidos de Cantabria (BSTC), Gob Cantabria, Consejería de Sanidad. (2017). Memoria Anual 2016.2 Recuperado de: http://www.fmdv.org/ficheros/esp/PlanActuacionDocumentos/86961D60-EDF6-82D354DD-254C1C11762A.pdf/

Bieri, B., Roosnek, E., Helg, C., Verholen, F., Robert, D., Chapuis, B., Passweg, J., et al. (2008) Quality of life and social integration after allogeneic hematopoietic SCT. Bone Marrow Transplant., 42(12), 819-27. Recuperado de: https://www.ncbi.nlm.nih.gov/pubmed/18711345

Blanes-Juliá, M., Gómez-Busto, D., Giménez-Martí, M. J., y Salavert-Lletí, M. (2010) Evaluación de la infección en el donante y en el receptor de trasplante de órgano sólido y de progenitores hematopoyéticos. En Aguado-García, J. M. (Ed.), Infecciones en pacientes trasplantados (131-58). Amsterdam, Nederlands: Elsevier.

Burgaleta-Alonso, C., Fernández-Jurado, A., García-Frade, J., Moreno-Chulilla, J., y MassóAsensio, P. (2010). Libro Blanco de la Hematología y Hemoterapia en España. Madrid: Edimsa. Recuperado de: http://www.sehh.es/images/stories/recursos/2016/libroblanco/libro_blanco_13_03_12.p df

Carreras, E. (2015) How I manage sinusoidal obstruction syndrome after hematopoietic cell transplantation. $\mathrm{Br} J$ Haematol, 168(4), 481-91. Recuperado de: https://www.ncbi.nlm.nih.gov/pubmed/25401997

Crespo-Fernández, S. (2016). Trasplante de progenitores Hematopoyéticos (Trabajo de Fin de Grado). Universidad de Cantabria, Santander.

Duarte, M. (2012) Trasplante autólogo de médula ósea. Acta Med Colomb, 37(4), 165-171. Recuperado de: https://www.redalyc.org/articulo.oa?id=163125377001 
Fuchs, E. (2012). Haploidentical Hematopoietic Cell Transplantation. En Hoffman, R., Benz, E. J., Silberstein, L. E., Heslop, H., Weitz, J., \& Anastasi, J. (Ed.), Hematology: Basic Principles and Practice (1617-1632). Amsterdam, Nederlands: Elsevier.

Fundación Josep Carreras contra la Leucemia. (2018). Guía del donante. Recuperado de: https://www.fcarreras.org/es/guia-del-donante-de-medula-osea_1205394.pdf

Fundación Josep Carreras contra la Leucemia. (2019). La donación de médula ósea. Recuperado de: https://www.fcarreras.org/es/donamedula

García, C. M., Mumby, P. B., Thilges, S., \& Stiff, P. J. (2012) Comparison of early quality of life outcomes in autologous and allogeneic transplant patients. Bone Marrow Transplant., 47(12), 1577-82. Recuperado de: https://www.ncbi.nlm.nih.gov/pubmed/22562082

Guzmán-Sánchez, V., Sánchez-Jiménez, E., y Ramos-Gutiérrez, M. E. (2014) Donación de médula ósea mediante aféresis de células madre hematopoyéticas. Evidentia, 11, 47-48. Recuperado de: http://www.index-f.com/evidentia/n47-48/ev9555.php

Holgado-Pérez, S. (2015). Variaciones de la masa ósea en el transplante de progenitores hematopoyéticos (tesis doctoral) Universitat autónoma de Barcelona, Badalona.

Ispizua, U., y Carreras-Pons, E. (2016). Trasplante de progenitores hematopoyéticos. En Rozman, C., \& Cardellach, F. (Ed.), Farreras Rozman. Medicina Interna (1730-48). Amsterdam, Nederlands: Elsevier.

Karp, J. Leukemia \&Lymphoma Society (LLS). (2011). Leucemia Mieloide Aguda. LLS, NY. Recuperado de: https://www.lls.org/sites/default/files/file_assets/sp_aml.pdf

Kaushansky, K. (1998). Thrombopoietin. N Engl J Med, 339(11), 746-54. Recuperado de: https://www.ncbi.nlm.nih.gov/pubmed/9731092

Kohn, D. B., \& Notarangelo, L. D. (2016). Hematopoietic Stem Cell Therapy. En Leung, D., Szefler, S. J., Bonilla, F. A., Akdis, C. A., \& Sampson, H. (Ed.),Pediatric Allergy: Principles and Practice (152-9). Amsterdam, Nederlands: Elsevier.

Kurmar, R., Godavarthy, P. S., \& Krause, D. S. (2018) The bone marrow microenvironment in health and disease at a Glance. J Cell Sci, 131(4), 1-8. Recuperado de: https://www.ncbi.nlm.nih.gov/pubmed/29472498

Linares, S., Moratalla, A., Romero, A., Pablos, J.M., López, P., Navarro, P.,et al. (2007). Información, ansiedad y depresión en pacientes sometidos a trasplante de progenitores hematopoyéticos (tph) en un estudio de intervención psicológica. Psicooncología, 4(1), 97$109 . \quad$ Recuperado de: https://revistas.ucm.es/index.php/PSIC/article/download/PSIC0707120097A/15750 
López-Granados, E., y Torres-Cañizales, J. M. (2015). Monitorización inmunológica en el trasplante hematopoyético. En Muro-Amador, M., y Martorrel-Pons, J. (Ed.), Monitorización inmunológica del trasplante (77-90). Amsterdam, Nederlands: Elsevier.

Maestud-Martín, G., Soldevilla-Esperanza, M.P., y España-Moscoso, T. (2015) Donación de cordón umbilical. Bancos públicos o privados. Investigación \& Cuidados, 13(33), 21-29. Recuperado de: http://www.index-f.com/icuidados/13/33021.php

NNNConsult. NANDA-NOC-NIC. (2019) Recuperado de: http://nnnconsult.com

Organización Nacional de Transplantes, Ministerio de Sanidad, consumo y bienestar social, Gobierno de España. (2017). Transplante de progenitores hematopoyéticos en 2017 (Memoria actividad ONT). Recuperado de: http://www.ont.es/infesp/Memorias/Memoria\%20TPH\%202017v2\%20con\%20terapia\%20 celular.pdf

Organización Nacional de Transplantes, Ministerio de Sanidad, consumo y bienestar social, Gobierno de España. (2018). Información Transplantes. Recuperado de: http://www.ont.es/informacion/Paginas/Trasplante.aspx

Patterson, E. R., \& Winters, J. L. (2012) Hemapheresis. En McPherson, R. A., \& Pincus, M. R. (Ed.), Henry's Clinical Diagnosis and Management by Laboratory Methods (751-82). Amsterdam, Nederlans: Elsevier.

Pérez-Fernández, L. (2016) Análisis del régimen jurídico español sobre la donación y depósito de la sangre de cordón umbilical (Trabajo fin de master). Universidad de Oviedo: Oviedo.

Rifón, J. J. (2006) Transplante de progenitores hematopoyéticos. An. Sis. Sanit. Navar., 29(2), 137-51. Recuperado de: http://scielo.isciii.es/scielo.php?script=sci_arttext\&pid=S113766272006000400013

Rovira, M., y Ruiz-camps, I. (2017) Infecciones en el trasplante de progenitores hematopoyéticos, Enferm Infecc Microbiol Clin, 25(7), 477-86. Recuperado de: https://www.sciencedirect.com/science/article/pii/S0213005X07743318

Ruiz-Argüelles, G. J., y Gómez-Almague, D. (2013). El trasplante de médula ósea, el premio Nobel y la muerte del Dr. Edward Donnall Thomas. Rev Hematol Mex, 14(1), 1-2. Recuperado de: http://www.medigraphic.com/pdfs/hematologia/re-2013/re131a.pdf

Ruiz-Seixas, M., López-Rodríguez, L., Praena-Fernández, J. M., Vázquez-Moncada, M., y QuijanoCampos, J. C. (2014) Calidad de vida relacionada con la salud en pacientes con trasplante de progenitores hematopoyéticos. Index de Enf, 23(4), 209-13.

Sánchez-Salinas, A. (2003) Estudio de eficacia y seguridad del lavado de progenitores hematopoyéticos de sangre periférica criopreservados mediante un sistema cerrado y automatizado, para transplantes autólogos (Tesis doctoral). Universidad de Murcia, Murcia. 
Sancho, J. M., Duarte, R., Medina, L., Querol, S., Manríd, P., y Sureda, A. (2016) Movilización de progenitores hematopoyéticos a sangre periférica con plerixafor en pacientes malos movilizadores. Med Clin, 147(5), 223.e1-223.e7. Recuperado de: http://www.elsevier.es/es-revista-medicina-clinica-2-articulo-movilizacion-progenitoreshematopoyeticos-sangre-periferica-S0025775316301671

Sociedad Española de Oncología Médica (SEOM). (2013). Toxicidad de los tratamientos oncológicos. Recuperado de: https://seom.org/guia-actualizada-de-tratamientos/toxicidadde-los-tratamientos-oncologicos?start $=6$

Scaradavou, A. (2018). Cord Blood Banking. En Shaz, B., Hillyer, C., \& Gil, M. (Ed.), Transfusion Medicine and Hemostasis: Clinical and Laboratory Aspects (549-57). Amsterdam, Nederlands: Elsevier.

Thachil, J., y Bates, I. (2018) Aproximación al diagnóstico y clasificación de los trastornos hematológicos. En Bain, B., Bates, I., y Laffan, M., Dacie y Lewis. Hematología práctica (497510). Amsterdam, Nederlands: Elsevier.

Vidal-Manceñido, M.J., (2011). Transplante de progenitores hematopoyéticos: tipos, indicaciones y toxicidad. En Martín-González, J., y Mosquera-González, M. (Presidencia), I Curso de Enfermería en Transplante de Progenitores Hematopoyéticos. Hospital Universitario Donostia. Recuperado de: http://www.osakidetza.euskadi.eus/r85sida01/es/contenidos/informacion/hd_publicaciones/es_hdon/adjuntos/Otras_Curso_Enf ermeria_TPH.pdf

Velardi, A., y Localleti, F. (2016) Trasplante de células madre hematopoyéticas de fuentes o donantes alternativos. En Kliegman R. M., Stanton, B., St. Geme, J., \& Schor, N. F. (Ed.), Nelson. Tratado de pediatría (1115-18). Amsterdam, Nederlands: Elsevier.

Young, J. H., y Weisdorf D. J. (2016) Infecciones en los receptores de trasplantes de células madre hematopoyéticas. En Bennett, J. E., Dolin, R., y Blaser, M. J. (Ed.) Mandell, Douglas y Bennett. Enfermedades infecciosas. Principios y práctica (3620-36). Amsterdam, Nederlands: Elsevier. 